\title{
Mulheres, poder e os incômodos best-
} sellers

\author{
Women, Power and The Incommodious Best-Sellers
}

Marcela Somensari Campana

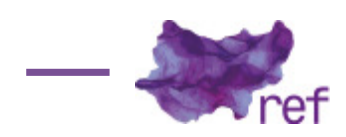

BEARD, Mary.

Mulheres e Poder: um manifesto.

Trad. de Celina Portocarrero. São Paulo: Planeta do Brasil, 2018.

A capa da edição brasileira do livro Mulheres e Poder (no original Woman \& Power) anuncia um "best-seller nos Estados Unidos e Inglaterra". Talvez, dado o perfil massivo desta categoria de livro, entenda-se que não Ihe caberia uma resenha crítica feita dentro dos moldes da academia. Pois essa barreira pode ser ultrapassada quando o histórico de sua autora vem à tona: Mary Beard é historiadora dedicada à antiguidade clássica e professora da Universidade de Cambridge. A legitimação da autora pelo seu vínculo com uma Universidade de forma alguma é incoerente à obra best-seller, pois coube à historiadora social construir duas falas que resultaria em um livro necessário e facilmente inteligível, sem as pretensões de construir uma grande obra, mas uma interessante reflexão.

Mulheres e Poder é um livro sobre gênero, um manifesto sobre o poder para as mulheres, composto por dois ensaios dedicados sobre o tema. Em ambos, o imaginário da antiguidade clássica é tido como constitutivo do imaginário da atualidade. No primeiro ensaio, de 2014, analisa o discurso e a voz como bases da elaboração e perpetuação da ideia de liderança e participação no poder. No segundo, de 2017, faz paralelos entre as questões das personagens femininas da antiguidade com as atuais mulheres em situação de poder.

Na primeira parte do livro - "A voz pública das mulheres" - a autora destaca seu interesse por estabelecer uma relação entre clássicos momentos de silenciamento de uma mulher, trazendo a discussão para nossa cultura ocidental contemporânea e seus espaços de poder, como a participação direta na política institucional, nos movimentos sociais e instituições financeiras. Apresenta exemplos de momentos da literatura clássica e registros históricos quando a presença da figura feminina, ligada à participação política, era algo estranho, digna de risos.

São poucos os exemplos de mulheres bem-sucedidas que se fizeram ouvidas, em comparação às várias situações que escancaram um padrão de violência, seguido por silenciamento. Para ser ouvida, é necessária uma aproximação com a masculinidade, como exemplifica Beard através da personagem de Mécia, que consegue se defender em um tribunal por ter uma "natureza masculina por trás de sua aparência feminina" (Mary BEARD, 2018, p. 23). Isso se dá, segundo a historiadora, também porque o poder do discurso e a capacidade de oratória eram características tidas como masculinas. A herança clássica fornece um "gabarito 
para pensar a respeito do discurso público" (BEARD, 2018, p. 32), mas a questão de gênero não pode ser excluída da reflexão.

Esta questão é aprofundada na segunda parte, intitulada "Mulheres no Poder". Avançando no tempo e nas representações, a autora busca direcionar seu olhar aos fundamentos culturais pautados na misoginia percebida na política ou no ambiente de trabalho e em suas formas mais diversas (por exemplo, imagens e falas) em manifestações contemporâneas. Para tal, analisa obras produzidas pelo imaginário da atualidade, desenhos, charges, teledramaturgia cômica, fotografias e notícias. Além da constatação de que as representações simbólicas do poder têm centralmente um homem, quando se trata de representar a imagem de uma mulher lhe é embutida características tidas como masculinas. Beard lembra da tragédia clássica Agamenon, de Ésquilo, na qual Clitemnestra é encarregada de liderar a cidade quando seu marido parte para a guerra. Automaticamente, Ésquilo passa a empregar "termos masculinos e a linguagem da masculinidade para se referir a ela" (BEARD, 2008, p. 67). A autora aproxima essa ideia da construção das figuras das mulheres candidatas a algum cargo no poder do Estado, da necessidade de caracterizá-las e de aproximá-las ao universo masculino, ainda tentando camuflar as características que constituem a própria formação do corpo feminino, como a voz mais aguda.

O ensaio então apresenta a figura mitológica da Medusa como um centro do imaginário coletivo quando se trata de deslegitimar a mulher no poder. Medusa representa "um dos maiores símbolos antigos do domínio masculino sobre os perigos destrutivos representados pela simples possibilidade do poder feminino" (BEARD, 2018, p. 77). O grande poder de Medusa, de petrificar quem a olha, e a saga de Perseu para destruí-la é tido pela autora como "uma implícita afirmação do poder fálico" onde "a dominação do macho é violentamente reafirmada contra o poder ilegítimo da mulher" (BEARD, 2018, p. 78). Essa figura foi usada como forma de ataque de quatro mulheres em posição de poder. Theresa May, atual primeira ministra britânica, teve sua figura comparada com Medusa pelo Partido Trabalhista que, em 2017, criou e disseminou uma caricatura e a apelidou de "Maydusa". Além dela, Angela Merkel e Dilma Rousseff também foram alvos da comparação, com montagens de seus rostos sobre a famosa tela de Caravaggio. Por fim, Beard $(2018$, p. 82) ressalta o maior exemplo da manifestação do imaginário tomado pela vitória do masculino Perseu sobre os perigos da feminina Medusa, que se deu ao fim da disputa eleitoral estadunidense de 2016, quando Donald Trump foi eleito presidente, e montagens da estátua de Benvenuto Cellini circularam com o rosto de Trump substituindo Perseu, segurando a cabeça decepada de Clinton como Medusa.

A autora não discute os direcionamentos políticos de cada uma dessas mulheres, destaca, entretanto, que suas gestões não foram necessariamente benéficas para as mulheres em geral. Os fatos apresentados apenas indicam que as formas de manifestação política, independente do viés partidário e do campo ideológico, se encontram na necessidade de reforçar a inviabilidade simbólica de uma mulher em cargo de chefia. Por isso, encaminha o ensaio para um desfecho no qual, ao invés de pregar uma maior participação feminina nas instituições que orbitam o poder burocrático, reflete sobre o que seria de fato uma transformação desse universo quando pensado na sua adequação às novas formas de poder feminino. Nesse ponto da discussão, propõe uma nova maneira de pensar o poder, fora da visão construída dentro da ideia da masculinidade como algo que carrega intrinsecamente a capacidade de se fazer líder, perspectiva que, consequentemente, exclui as mulheres. Beard entende que "não se pode inserir as mulheres numa estrutura que já está codificada como masculina; é preciso mudar a estrutura" (BEARD, 2018, p. 93). Enxerga a possibilidade de mudança por meio da construção de uma ideia de poder não como substantivo, mas como verbo, ou seja, não algo que se tem, mas algo que se faz, pensandoo de forma colaborativa e dissociando-o do prestígio público.

A obra se faz necessária por indicar que o processo de exclusão da mulher dos centros das decisões tem sua origem em um passado distante, mas ainda não foi superado. Acima de tudo, indica que apenas a atuação pontual de mulheres a estes centros não poderá resolver questões estruturais que tornam vulneráveis um grupo de pessoas baseado em algo não controlável, como - gênero. A questão final do livro trata da necessidade de transformações profundas das formas que constituem as relações políticas e sociais.

Além disso, para as/os leitoras/es brasileiras/os, o uso do exemplo de Dilma Rousseff permite que se vá além na reflexão proposta pelo livro, buscando uma aproximação maior da obra com o contexto recente do Brasil. Na primeira parte, quando são narrados exemplos de obras clássicas e suas representações irônicas da possibilidade de dar voz às mulheres, indica uma comédia de Aristófanes - $A$ assembleia das mulheres ou $A$ revolução das mulheres - na qual as mulheres deveriam assumir o controle da política onde "parte da graça era que as mulheres não sabiam falar adequadamente em público - ou melhor, eram incapazes de adaptar sua linguagem pessoal (que, no caso, era amplamente ligada a sexo) ao sublime idioma da política masculina" (BEARD, 2018 , p. 91). Esse exemplo, aproximado ao momento brasileiro, remete ao processo de impeachment da primeira presidenta eleita no Brasil, Dilma Rousseff. Para além das questões relacionadas ao procedimento legal institucional, aqui se tenta relembrar a movimentação civil de apoio à queda 
da recém-reeleita Chefa de Estado através de uma campanha de ironização e de desconstrução de sua imagem de líder, de pessoa mentalmente capaz. Essa construção imagética era feita por meio de recortes de falas oficiais, montagens degradantes e piadas sobre sua capacidade de falar, supostas falhas de coesão, ou falho domínio da oratória.

Essa aproximação da obra com o contexto brasileiro não poderia deixar de ser realizada. A autora em certo ponto afirma pretender "ir além do simples diagnóstico de misoginia" (BEARD, 2018 , p. 20) ao realizar suas análises, apesar de entender que, por vezes, essas manifestações quando não são misóginas, derrocam em outras que o são. Sobre a importância da obra aqui resenhada, enfatiza-se, precisamente, a indicação de que cercear a voz das mulheres nas esferas públicas e na participação política com ataques misóginos e ironias descabidas quanto à sanidade e à capacidade intelectual têm efeitos distintos ainda quando se coloca em contraste questões de classe e raça. Enquanto a ironização das mulheres em situação de poder as constrange em sua posição, nas camadas mais vulneráveis da sociedade encontra-se uma violência direta que marca com sangue o silêncio. Dilma foi deposta; Marielle, violentamente executada. ${ }^{1}$

\section{Referência}

BEARD, Mary. Mulheres e Poder: um manifesto. Trad. de Celina Portocarrero. São Paulo: Planeta do Brasil, 2018.

\section{Marcela Somensari Campana (iD) 0000-0002-6648-9190}

Mestranda no Programa de Estudos Pós-Graduados em Ciências Sociais na PUCSP, com ênfase em Ciências Políticas

Bolsista CNPq. Pesquisa relações entre produção cultural, imagens e representações políticas. É bacharela em Marketing pela Universidade de São Paulo e especialista em Sociopsicologia pela Fundação Escola de Sociologia e Política de São Paulo.

Pontifícia Universidade Católica de São Paulo, Programa de Estudos Pós-Graduados em Ciências Sociais,

R. Monte Alegre, 984 - Perdizes

05014-901 - São Paulo - SP - Brasil

+55 (11) 3070-8000 - csopos@pucsp.br

marcelascampana@gmail.com

\section{COMO CITAR ESSE ARTIGO DE ACORDO COM AS NORMAS DA REVISTA}

CAMPANA, Marcela Somensari Campana. "Mulheres, poder e os incômodos best-sellers". Revista Estudos Feministas, Florianópolis, v. 27, n. 1, e56487, 2019.

\section{CONTRIBUIÇÃO DE AUTORIA}

Não se aplica

FINANCIAMENTO

Não se aplica

\section{CONSENTIMENTO DE USO DE IMAGEM}

Não se aplica

APROVAÇÃO DE COMITÊ DE ÉTICA EM PESQUISA

Não se aplica

\section{CONFLITO DE INTERESSES}

Não se aplica

${ }^{1}$ Referência ao crime político cometido contra a vereadora da cidade do Rio de Janeiro, Marielle Franco, e de Anderson Pedro Gomes em 14 de março de 2018 . A autoria e as motivações não foram divulgadas até o fechamento desta resenha. Marielle representava a voz das mulheres negras das periferias do Rio de Janeiro. 


\section{LICENÇA DE USO}

Este artigo está licenciado sob a Licença Creative Commons CC-BY. Com essa licença você pode compartilhar, adaptar, criar para qualquer fim, desde que atribua a autoria da obra.

\section{HISTÓRICO}

Recebido em 23/04/2018

Revisões requeridas em 30/06/2018

Aceito em 04/1 1/2018 